\title{
Commercial Space with Technology Maturation
}

\author{
Carey M. McCleskey ${ }^{*}$ and Russel E. Rhodes (ret.) ${ }^{\dagger}$ \\ NASA Kennedy Space Center, Florida, 32899 \\ And \\ John W. Robinson ${ }^{\ddagger}$ \\ Propellant Supply Technology, Seal Beach, California, 90740
}

\begin{abstract}
To provide affordable space transportation we must be capable of using common fixed assets and the infrastructure for multiple purposes simultaneously. The Space Shuttle was operated for thirty years, but was not able to establish an effective continuous improvement program because of the high risk to the crew on every mission. An unmanned capability is needed to provide an acceptable risk to the primary mission. This paper is intended to present a case where a commercial space venture could share the large fixed cost of operating the infrastructure with the government while the government provides new advanced technology that is focused on reduced operating cost to the common launch transportation system. A conceivable commercial space venture could provide educational entertainment for the country's youth that would stimulate their interest in the science, technology, engineering, and mathematics (STEM) through access at entertainment parks or the existing Space Visitor Centers. The paper uses this example to demonstrate how growing public-private space market demand will re-orient space transportation industry priorities in flight and ground system design and technology development, and how the infrastructure is used and shared.
\end{abstract}

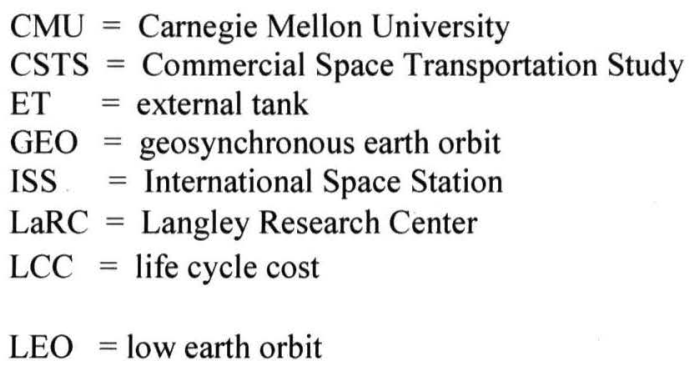

\section{Nomenclature}

$\begin{array}{ll}\text { OMS } & =\text { orbital maneuvering system } \\ \text { OTV } & =\text { orbital transfer vehicles } \\ \text { RCS } & =\text { reaction control system } \\ \text { R\&D } & =\text { research and development } \\ \text { SPST } & \text { Space Propulsion Synergy Team } \\ \text { SRB } & =\text { solid rocket booster } \\ \text { SSP } & \text { Society for Science \& the Public } \\ \text { STEM } & =\text { science, technology, engineering, and } \\ \text { mathematics } & \\ \text { STS } \quad \text { space transportation system } \\ \text { TRL = technology readiness level } \\ \text { U.S. = United States }\end{array}$

\footnotetext{
* Aerospace Technologist, Engineering and Technology Directorate, NASA Kennedy Space Center, mail code NE-D3; AIAA Senior Member.

${ }^{\dagger}$ Aerospace Technologist, NASA Kennedy Space Center, retired, and AIAA Senior Member.

${ }^{\ddagger}$ Propellant Supply Technology; chairman, Space Propulsion Synergy Team, and AIAA Associate Fellow.
} 


\section{Introduction}

$\mathrm{M}$ UCH attention and public funding has been paid recently to commercial space launch. The National Aeronautics and Space Act, in its congressional declaration of policy and purpose, addresses commercial use of space: "Congress declares that the general welfare of the United States requires that the Administration [i.e., NASA] seek and encourage, to the maximum extent possible, the fullest commercial use of space." Rather than focusing on commercial space launch capabilities, this paper more fully explores the commercial use of space.

A space venture is examined that shares the large fixed cost of operating space flight infrastructure with the government. In this paper we focus on innovative uses-commercial uses-that create a growing demand for (1) more affordable, capable, and responsive infrastructure, (2) greater access by the public, and (3) the need for the national space flight infrastructure made available for improvements (both space-based and Earth-based infrastructure). A major emphasis would be focused on improved space transportation system operability and supportability, thus reducing operating cost and total ownership cost for both the government and the private sector. Our approach is to encourage the teaming or forming a partnership of government and a commercial space transportation entrepreneur with separate objectives to share a common ground infrastructure, i.e., large fixed cost provided by the government partner. This approach also suggests the commercial partner provide the flight demonstration of the advanced technology (upgrading his system) during one of their flight operations focused on lowering the operational cost of the transportation system. This achievement is to make the United States (U.S.) more competitive in the world market while reducing the U.S. government's life cycle cost of space operations beyond low earth orbit.

The particular commercial space venture investigated would engage youngsters that would stimulate their interest in the science, technology, engineering, and math (STEM) fields of education through access points at publicly- or privately-run science centers, planetariums, museums, entertainment parks, or existing visitor facilities located at NASA space centers. Various methods of engagement are examined from the perspective of market growth and transportation infrastructure demand, rather than an implementation/proposal perspective. It will demonstrate a different way of looking at the space transportation market beyond the near-term satellite deployment market.

We will first discuss the approach taken in Section II, followed by an explanation of the public-private space enterprise example in Section III. This will be followed by an outlining of specific space transportation needs, goals, and objectives in Section IV, which are established from the space market example case. In Section V a discussion of how partnering and partitioning of the space transportation infrastructure, for both public and private commercial use can help not only make the service more affordable, but through dedication of assets for continuous improvements, technology maturation can more naturally be accomplished to sustain the industry. A discussion of the advanced technology maturation process will be found in Section VI. Finally, in Section VII several observations and conclusions are drawn from the example case including space transportation implications, and partnering the commercial with government to achieve lowering the cost of earth to orbit transportation.

\section{Approach}

This section of the paper discusses the approach in establishing a viable space market within a broad field of potential new space markets. Individually and combined with other new on-going markets, this approach integrated with a common space transportation system (STS) can provide a sustainable commercial/government STS with planned technology improvements and upgrades for both near and far term space markets. The approach taken incorporates a synopsis of a course of action, events and situations that can be integrated with on-going new space markets and illustrate how events might unfold with the objective of achieving an effective and sustaining STS for now and the future. Using the ground-based space theme parks as our_initial new space market example we will address key considerations including space market identification, time planned scenario generation, growth in demand and space transportation requirements, partnering and partitioning infrastructure for both public and private use and technology maturation. 


\section{A. Space Market Identification}

We start with identifying a new space market or new space industry. The space market is distinguishable from the space transportation market in that it operates at a destination or origination point in space needing transportation to and from those locations. The goods and services that supply that movement form the space transportation market, while the goods and services at the space location is, for the purposes of this paper, identified as the space market. The need for new markets today is seen in the trend charts in Attachment 1.

Several good sources of space market and new space industries are available. We will examine one that was identified in the 1990s in a Commercial Space Transportation Study (CSTS). ${ }^{1}$ Specifically, we are interested in a ground-based space theme parks kick-starting and igniting interest (i.e., demand) for access to the space frontier by everyday citizens across the globe; but particularly aimed at stimulating the imaginations of our youth. As we will see, there is both a public and a private commercial set of opportunities associated with this particular market-and we will want to take advantage of this market characteristic when we translate the growth needs of this market to transportation system needs, goals, and objectives. In summary, the market identified is:

\section{Ground-Based Space Theme Parks}

\section{B. Scenario Generation and Segmentation of Timeframe}

With a market identified - the ground-based space theme park market-a representative set of market concepts are documented to establish quantified scenarios for further economic, business, and systems analysis.

However, it would be unwise to assume for emerging space markets that the systems and the transportation characteristics will continually support rapid growth, when it occurs, with a stagnant set of capabilities. Continuous improvement of system responsiveness, availability, dependability, and most importantly, goods and services that are affordable and desirable to the space market customer is what will sustain the market.

One method for planning this aspect is to look farther into the future than the life cycle of existing or near-term markets and system capabilities. By building separate near-, mid-, and farther-term scenarios-each with its own set of leaps in assumptions about customer desires, affordability, and systems capabilities - it will be recognized that a growing series of investments are required for continual improvements and market sustainment. Without such planning, the markets quickly stagnate after initial uniqueness or usefulness begins to fade. There will be a set of these scenarios associated with three defined planning horizons:

- Near-term: Ground-Based Space Access Point Growth

- Mid-Term: Ground-Based Space Theme Park Growth

- Farther-Term: Space Activity Growth Enabled by Ground-Based Space Activity

The basis for these definitions is not defended for the purposes of this paper, since this merely an example case market being illustrated. A real world business plan would, of course, substantiate these selections based on thorough market studies and analyses with detailed surveys, market elasticity curves, and other economic analyses.

\section{Measuring Growth in Demand and Translating to Space Transportation Needs, Goals and Objectives}

Plotting out the growth scenarios for our space market example requires pinpointing the revenue generating devices and uses by customers of those devices - the space activity. A key question will be: how can interest, usefulness, or increase in the quality of life emerge from growth in these ground-based space activities?

Once a set of revenue generating devices are identified, how are they deployed to space? Is there anything returned from space? How are they maintained or replenished as they wear out or fail? How much infrastructure is required on Earth and in space to keep the activities going — and growing?

Answers to these questions will allow an informed set of figures to be pulled together and create a profile over time of the mass, volume and transportation services, in general, required for initial start-up, sustainment, and expansion phases.

A key measure will be the required space system mass throughput by space destination. Note the measure here is not mass, but mass per unit time - throughput. This is not a deployment mission being established, but a whole market of missions - some are unique and exciting deliveries. Many more are likely routine scheduled deliveriesless interesting from a general public point of view (unless, of course, the public considers the earning of substantial dividends of interest). A second measure will be the total annual amount the enterprise can afford for the space transportation portion of its annual enterprise costs; or, played against the annual throughput profile, the allowable cost-per ton. Finally, there should be a high, medium, low probability set of assumptions documented around these parameters. 
Now the space transportation systems analysis can begin by taking what is essentially a design reference market and searching for specific transportation functions and balancing key goals and objectives. Among the items needing balance are transportation system capability, utilization, and reliability in terms of utilized flight rate, vehicle payload capacity, flight reliability, and operational availability. Additionally, some knowledge of average payload load factors, cargo container tare weights, and so forth are needed.

All of these space transportation system requirements are documented for each planning horizon: near-, mid-, and farther terms.

\section{Partnering and Partitioning Infrastructure for both Public-Private Use and Technology Maturation}

The nature of any major public or private transportation system or commercial enterprise, regardless of whether it is land, sea, or air mode, is that there are operations by users acting directly on the transportation vehicle and its interfacing support equipment, facilities and services; and there is a support infrastructure and supply network necessary to be maintained to enable the direct operations. The total system must not only be low cost, but also productive and dependable. Separating the direct functions and assets from the support functions and assets allows flexibility in who provides what across the total infrastructure, or architecture.

Sharing fixed assets that support more than one operation is an obvious opportunity for public-private sharing of useful infrastructure when it comes to space access. Another opportunity arises when it is realized that any excess capacity could be put to use for continuous improvement. Dedicating, or partitioning, a small set of vehicle and ground support assets for this purpose is crucial in a achieving the mid- and farther-term planning horizon objectives. By allowing routine space flight testing of needed system operability and supportability improvements, technology maturation occurs more naturally and avoids the valley of death between what is desired but unattainable and what is on the shelf.

\section{Example Market Case: Ground-Based Space Theme Parks}

\section{A. Commercial Space Transportation Study (CSTS) and LunaCorp Background}

The space theme park market area was originally conceived in the Commercial Space Transportation Study (CSTS) of 1994 as a mass market using a station in space providing entertainment services. Upon further examination, though, it evolved to include both ground and space-based destinations, including access points on Earth with a space theme for the purpose of education and entertainment. Section 3.6.6 of the CSTS identified a market opportunity to take advantage of near-term capabilities and assets to establish ground-based markets with a transition into a space-based entertainment center. In the near term, space adventures could be created on Earth in the form of tele-presence and virtual reality techniques. Bear in mind this study was released before the internet took off-just as Netscape and Windows 3.1 arrived on the market place. The opportunity was viewed by the CSTS Alliance ${ }^{1}$ conducting the study as providing a near-term introduction into the future market for on-orbit theme parks with unique attractions that provide entertainment and accommodations for space tourism and public space travel.

Soon afterwards, in the 1996 time frame, a small, aggressive venture capital operation, known as LunaCorp, began partnering with the Robotics Institute of Carnegie Mellon University (CMU) and gaining a contract with Mitsubishi Corporation of Tokyo to pursue the aforementioned market identified by CSTS a couple years earlier. One of their concepts was to deliver a remote controlled moon rover that would feed live high-definition television

\footnotetext{
${ }^{1}$ Representatives of six aerospace companies (Boeing, General Dynamics, Lockheed, Martin Marietta, McDonnell Douglas, and Rockwell) and NASA met in March 1993 at NASA's Langley Research Center (LaRC) to discuss means by which a new, commercial space transportation system might be developed. A perception was held by government and industry at the time that a new, state-of-the-art launch system could provide an order of magnitude reduction in launch costs and that a reduction of that magnitude would cause the equivalent of a space industrial revolution with a substantial increase in users and traffic. The group meeting at NASA LaRC concluded that to become economically viable, a new launch system must generate new commercial markets. This group, now known as the Commercial Space Transportation Study (CSTS) Alliance, established the need for a market exploration study to identify potential customers, determine price elasticity of demand, and assess the commercial business opportunities for such a future launch system. This plan was briefed to NASA Administrator Dan Goldin on April 30 , 1994, and in May the partnership between NASA and the companies began.
} 
images of the moon "back to theme parks and other venues here on Earth where people could pay to a part of the adventure." ${ }^{2}$ Figures 1 through 3 provide a visual sense of the ground-based space theme park idea.

Another proposal was offered to consider use of the Shuttle Columbia in a public-private mode where the vehicle would be dedicated as an improvement platform for greater operability and affordability while delivering commercial cargo at marginal cost with low cost solid upper stages for periodic deliveries to the Moon launched from the Orbiter in low Earth Orbit. ${ }^{3}$

However, ultimately these types of pursuits failed, primarily because of the high chartered flight costs and lack of flight availability of space access needed to continually deliver revenue generating devices that could be sustained on a continual basis. All of which seemed to confirm a customer price and access barrier to opening up commercial space markets.

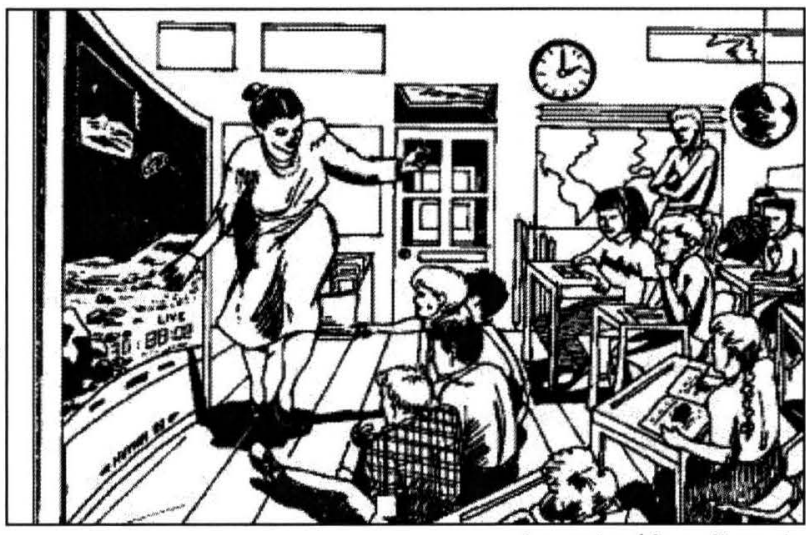

International Space Enterprises Figure 1 - Classroom viewport of science demonstrations-live from the Moon.

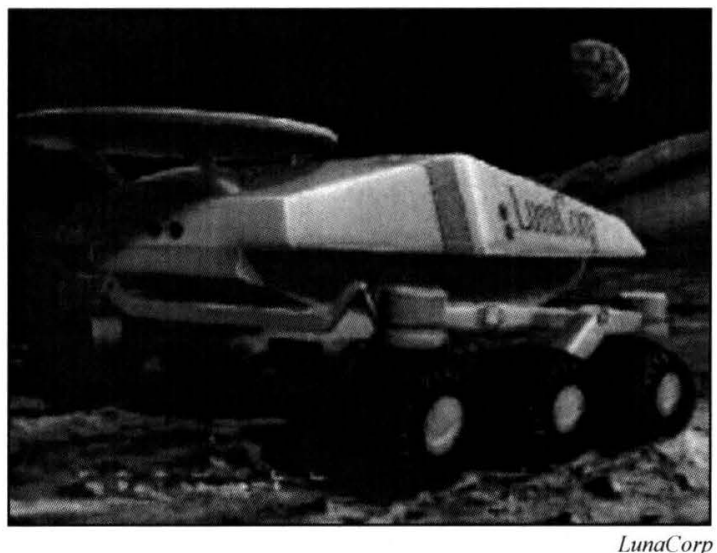

Figure 2-Commercial moon rover.

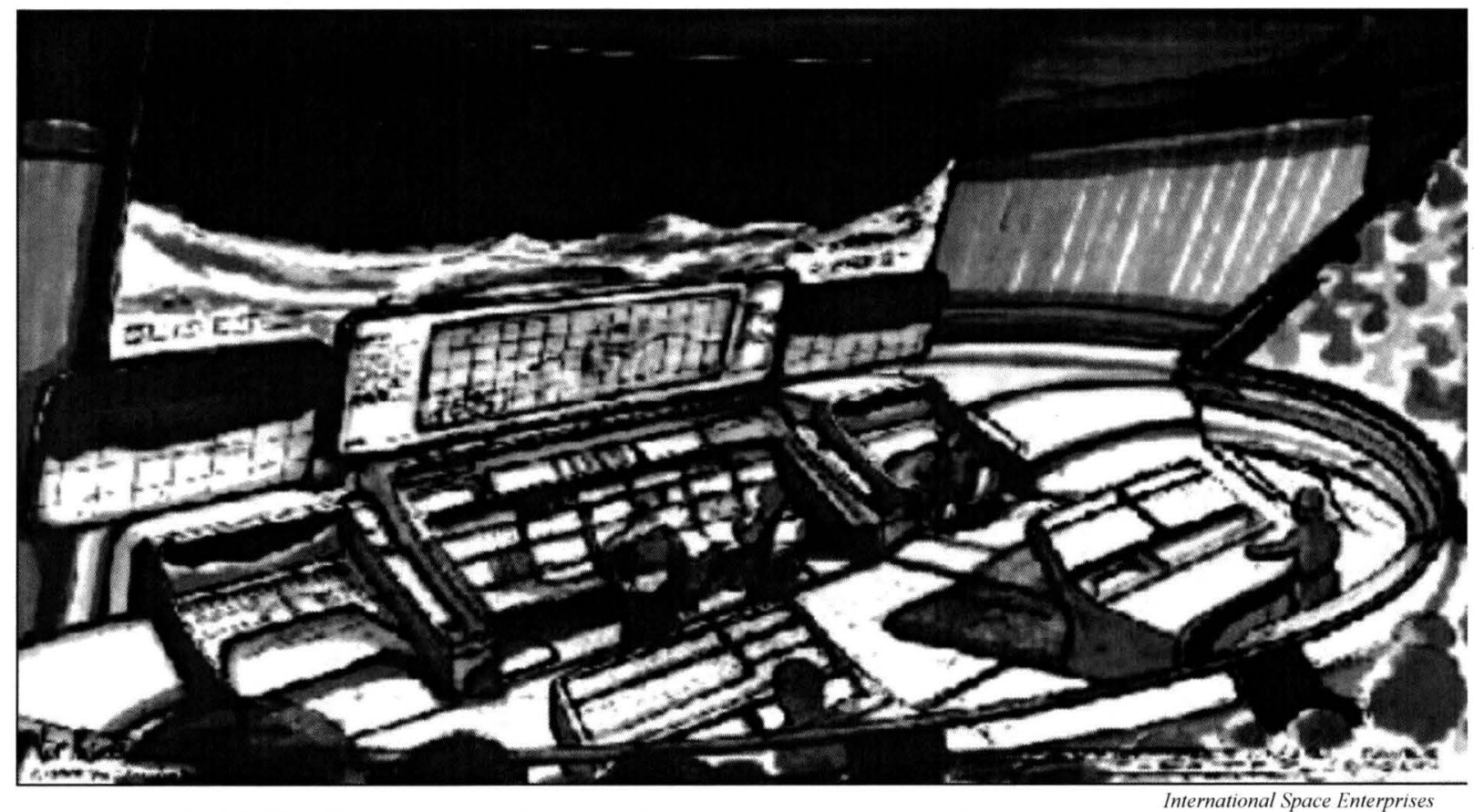

Figure 3-High definition live lunar excursion, controlled by a public or private lunar excursion leader at: science centers, planetariums, NASA space center visitor's centers, and entertainment theme parks. 


\section{B. Near-term and Mid-term Growth in Ground-Based Space Access Points (Start-up and Sustainment Growth)}

With this background in hand, and with renewed interest in promoting and public funding of commercial space ventures, a shared public-private (which in a financial sense is already occurring) is forwarded as an illustration of market-driven space transportation architecture and technology requirements.

\section{Lunar Surface Market Description}

The concept is to deploy a small set of fixed or mobile devices that are unmanned on the Moon. Unlike the many uniquely-designed and fabricated planetary probes and Mars rovers, these would be targeted for routine production and space deployment. These would be at the heart of revenue generation, since they establish a small remote base that slowly at first lands a few rovers, but then begins to collect and maintain a collection of co-located services, such as: energy supplies and charging stations for the mobile rovers, communications relays, remotely landed data storage servers, small telescopes, microscopes, very small furnaces, small regolith brick formers. Lunar Orbit and Earth Orbit dedicated Communications Platforms

The market concept also establishes a growing commercially-operated presence in lunar orbit and in Earth orbit to provide live feeds at all hours of the day somewhere on the Earth where "edutainment" attractions are gathering for live shows or other live access, such as classrooms and other public forums. These devices could also then serve traditional government space exploration activity, or other commercial enterprises.

What all these functional "seeds" form is the basis for whole new industries in up-coming market horizons in the mid-term; say, 5 - 10 years following initial deployment, and a farther-term horizon $10-20$ years following initial start-up. These new industries formed from the very small, initial revenue-generating device that is perhaps as small as the various Mars rovers will begin to grow and spin-off entirely new ventures; e.g., lunar power supply companies, imaging services, large, centralized data processing and communications services and infrastructure, building and construction material supply. All while the public views, generates, and participates in their growth and emergence from seemingly primitive, but globally participative lunar surface activity.

\section{Low Earth Orbit (LEO) Market Description}

The market concept is to begin creation of several new destinations and capabilities concentrated in Earth orbit. These may include propellant depots and large space service platforms.

For propellant depots, operations could be viewed and demonstrated in ground-based space access points.

For large space service platforms construction of routinely accessed geosynchronous earth orbit (GEO) service platforms for communications, Earth observation, and global positioning. Such platforms would be unmanned and either robotically- or human-tended platforms where key revenue generating components can be upgraded: for example, transponders, optical equipment, antennas, rectifiers, and processors. This would avoid the need for ventures paying for hand-crafting entire "satellite busses" with dedicated propulsion, avionics, attitude control systems and so forth just for their device. They are interested in owning a delivered transponder, and chartering a seven-year long spacecraft systems engineering program. Service providers are looking to own a space in which to operate. Concentrated, serviced space platforms offer that capability, and avoid the problem of space debris and the complications of its mitigation

\section{In-space Planetary and Astronomical Observation Market Description}

The market concept is to re-use many of the Jet Propulsion designs and begin low cost production for feeding live ground-based space theme park material into the attractions. This could include the audience, by consensus directing a set of space telescope viewing options while the planetarium director clues the audience in on the wonders they are observing. Similarly, accessing Mars or Jupiter orbiter images live (albeit significantly delayed), leaves the participating customers and public more engaged and knowledgeable of the space frontier. It's not just for the benefit of the youth; it's also for the benefit of those who vote and have the power of the purse.

\section{Ground-based Access Point Market Description}

The market concept is to begin establishment of all kinds of access points on Earth for: youth and youth organizations, their parents and grandparents, teachers, professors, church groups, and non-profit scientific and educational institutions, such as the National Geographic Society; Society for Science \& the Public (SSP), formerly known as Science Service, and many others. Since it would be undesirable to leave the space-based assets idle while the United States retires for the evening, a global search would be on to establish all these same types of access points aimed at the same market of individuals and organizations-across the Americas to Europe, and from Africa to Asia and Australia. All would be able to access the growing number of space-based assets, because there would be a growing global demand for that access.

However, the uniqueness wears off with easily-implemented services and a new level capability will be desired, and hopefully demanded. This will end the start-up phase and a mid-term market phase will need to take over. 

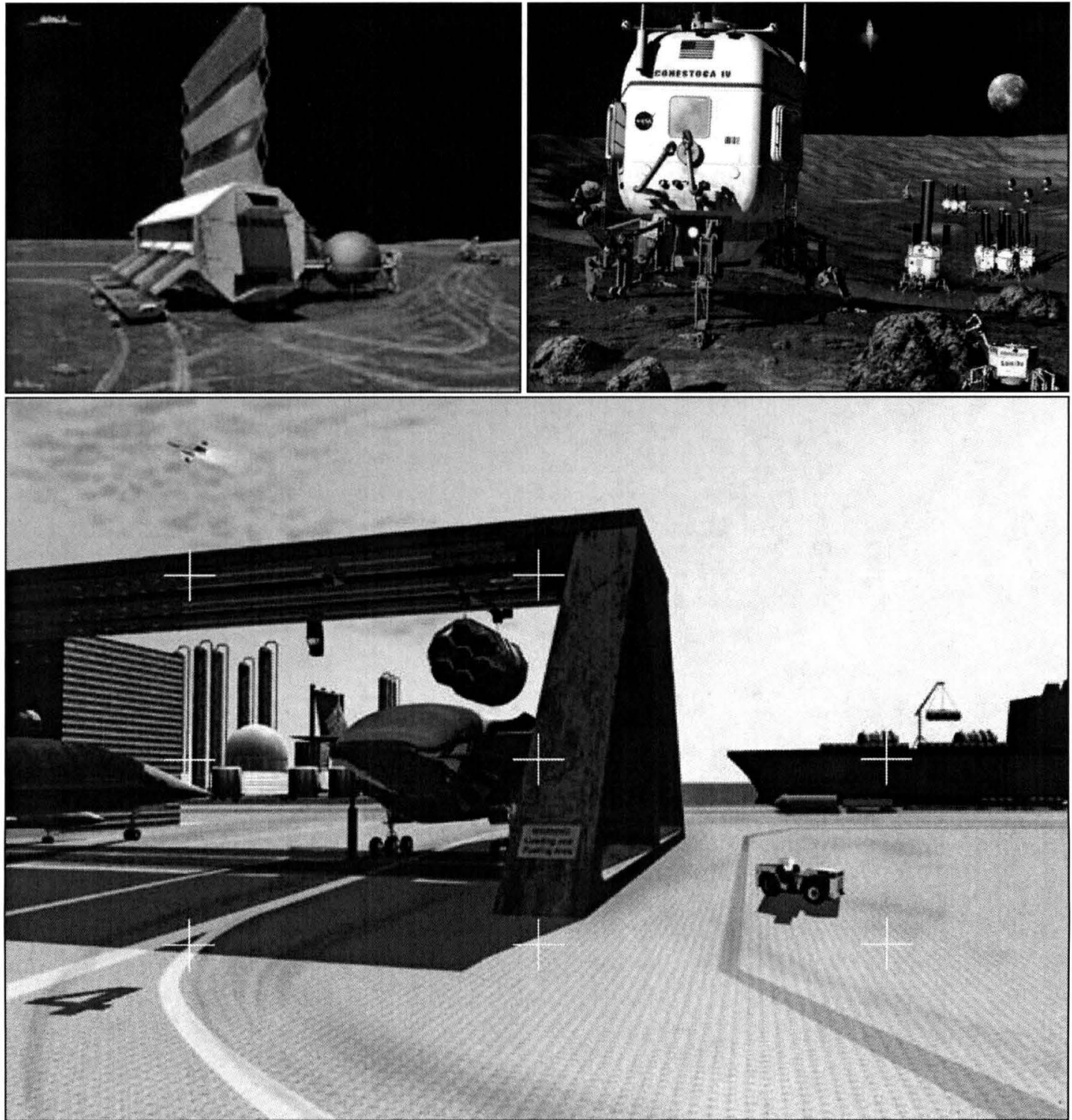

Figure 4-Pat Rawlings' renderings of hexagonal space structures, including the "Habot" in the upper right; a Mobile Lunar Base Concept (courtesy of John Mankins, NASA HQ, and Neville Marzwell, Jet Propulsion Laboratory). At bottom, Pat Rawlings rendered for NASA's Vision Spaceport project a truly multi-modal port: a convergence of land, sea, air, and space deliveries of containerized cargo.

\section{Farther-term Growth in Publicly-Accessed Space Theme Parks (Expanded Growth and Settlement)}

Looking a number of years beyond the ground-based space access point era, a sufficient period of time in technology investments for space travel may enable more and more human access to space. This may go beyond the typical consideration of "space tourism." Public space travel may occur right here on Earth first.

Three-dimensional live television and other capabilities may allow ground-based access from space theme parks for all kinds of serious exploration and settlement enterprises, as well as just plain fun kind of access, like simulating bouncing around on the Moon or enjoying celestial vistas that rival the Grand Canyon experience.

Many of these types of experiences will require delivery and space-based operations and maintenance of beyond the reach of today's space transportation and spacecraft systems capabilities. Construction of large-scale surface 
operations and surface bases may be enabled by the accumulation of infrastructure and services created during the start-up and sustainment growth market phases. Initially the ground-based space access points will be services by robotic, small-scale infrastructure, probably not much larger than the scale of equipment delivered (excluding the Lunar Module) at the Apollo science equipment sites. At some point, though, capabilities will grow to make larger bases and "settlements" to emerge.

\section{From Design Reference Market to Space Transportation Needs, Goals, and Objectives}

\section{A. Market Demand Profiles}

Taking data from the CSTS ${ }^{4}$ and applying an inflation factor of 1.8 from 1992 to $2013^{5}$, Fig. 5 informs us of the payload mass requirements (i.e., the space transportation market demand) in terms of annual throughput by mass, and how the demand grows with increases in affordability.

\section{Example Case Market Demand Curve}

(metric tons per year)

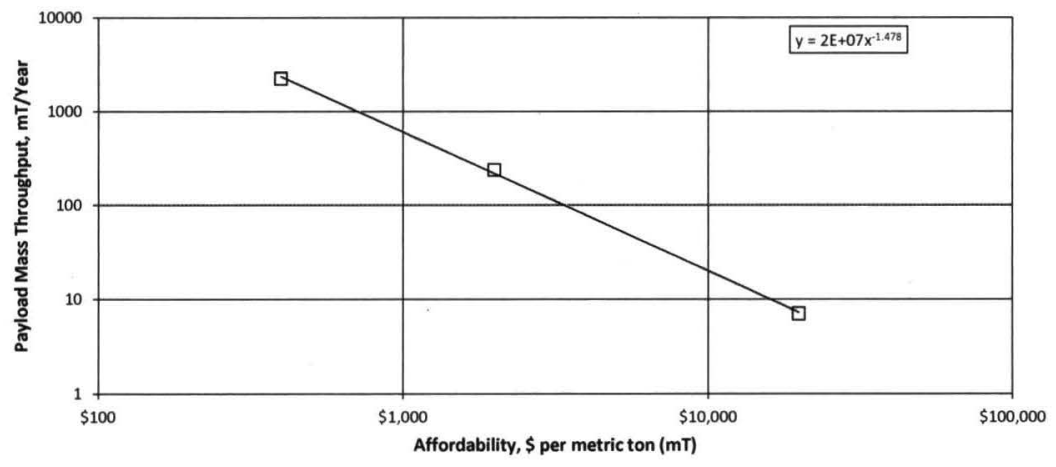

Figure 5-Market elasticity plot of expected payload demand by mass vs. cost-per-ton.

\section{B. Space Transportation Needs, Goals, and Objectives}

\section{General Space Market Needs}

From the descriptions of the markets the following types of transportation needs emerge:

a) Telecommunications services-provided by large-scale, assembled transponder farms that are routinely attached or upgraded, rather than dedicated launches for unique satellite busses dedicated to a small number of transponders

b) Conducting advanced space research, e.g., large-scale astrophysics platforms, artificial gravity assemblies, space solar power arrays, and advanced in-space propulsion experiments

c) Construction, servicing, repair and expansion of inhabited space facilities, public space travel and, of course, space settlements.

d) Construction, servicing, repair and expansion of in-space transportation waypoints, such as propellant depots, and spacecraft assembly facilities for heliocentric transportation systems.

e) Space resource exploration and commercial harvesting, such as: space solar power; near-Earth object exploration and mining; construction and operation of lunar-planetary bases.

\section{Derived Space Market Requirements of the Space Transportation Industry}

A list of derived requirements and rationale from the foregoing list can be created. Note: A similar list is found in another Space Propulsion Synergy Team (SPST) AIAA technical paper. ${ }^{6}$

(1) Frequent and high volume cargo deliveries

Rationale: Required for enterprises that resupply and/or assemble for revenue-generating opportunities. 
(2) Safe, comfortable, unburdened launch and landing experience for the passengers Rationale: Required for enterprises attracting passengers

(3) Dependable arrivals and departures at the space enterprise locations Rationale: Required for enterprises depending on resupply for sustainment.

(4) Ability to conduct routine assembly, servicing, and repair activities at a variety of destination locations (possesses large-scale in-space element and component handling devices)

Rationale: Required for enterprises depending on servicing and repair, as well as mobile construction capabilities for expansion of their space enterprise, wherever it is located.

(5) A means of routine, affordable transportation from one Earth orbit to another Earth orbit Rationale: Provide low-cost in-space transport from LEO to geo-stationary Earth orbit (GEO), or other useful locations - a space-based orbital transfer service using orbital transfer vehicles (OTVs).

(6) Clean, effluent-free environment around arriving spacecraft

Rationale: Required of space transportation system to avoid space transportation architecture interrupting or degrading the operation due to spacecraft subsystem effluents, corrosive attitude control exhaust, etc.

3. Goals and Objectives for Space Transportation

With the general needs for space transportation identified, quantifiable goals and objectives must be established. For the near-term,

Affordability Goals

Near-term Market Goal/Assumption ${ }^{7} \sim \$ 3,000 / \mathrm{kg}$ to $\operatorname{LEO}(\sim 6,000 / \mathrm{lb})$

Mid-term market (next 5-10 years) $\mathrm{Goal}^{8}<\$ 2,200 / \mathrm{kg}(\$ 1,000 / \mathrm{lb})$

Farther-term market $\left(10-20\right.$ years) Goal $^{9}<\$ 220 / \mathrm{kg}(\$ 100 / \mathrm{lb})$

Productiveness Goals

Near-term Goal/Assumption: assume Falcon-Heavy at about $250 \mathrm{mT} / \mathrm{Year}_{\mathrm{pad}}{ }^{10}$

Mid-term Goal $>500 \mathrm{MT} /$ year/string of assets $(\sim 1.1 \mathrm{M} \mathrm{lbs} / \text { year per string })^{11}$

Farther-term Goal $=1,000 \mathrm{MT} /$ year/string of assets $(\sim 2.2 \mathrm{M} \mathrm{lbs} / \text { year per string })^{12}$

Based on these payload delivery goals for the system, specific flight architecture design objectives can now be set. The vehicle payload capacity, the flight rate capability, and the total ownership cost to the operator of the system can all be traded to meet the objectives. However, these sizing objectives are objectives are beyond the scope of this paper. At this point the SPST refers you to other papers in our AIAA JPC series. ${ }^{13,14,15,16}$

\section{Partnering and Partitioning Infrastructure for both Public-Private Use and Technology Maturation}

Suggested is an approach to partnering where the determination of the ratio of fixed cost (government provided) vs. variable cost (commercial provided) is key. The space launch rate capability per year with a given single string system of present designs can vary from $\sim 10 \%$ to $30 \%$ variable cost from very low vs. more moderate launch rate capability. Market availability will also have an influence on this annual launch rate which will determine if the commercial provider can achieve his maximum potential. Some of the influences may be the backlog of space customers waiting for an opportunity to fly with a given space transportation system or the total backlog of customers in the world looking for an opportunity to get into space. The concept of performing such an operation with one of the Shuttle Orbiters was considered a few years ago, but the time wasn't appropriate as the focus by NASA leadership at the time was strictly on the use of the international space station (ISS) to perform scientific advancements for industrial groups that show interest.

A. Why combine these commercial space operations with Government space Technology maturation?

Government provides the infrastructure as in other transportation needs of this country - highways. The NACA/NASA developed many technologies for the aircraft industry that were common to all who wanted to build aircraft. NASA is still developing advanced technology for this industry. The infrastructure needed to do this 
technology development is very expensive to build and maintain; therefore, no single industry unit should bare this expense as the return on investment isn't attractive for entrepreneurial investment. Therefore, progress can only be achieved if the government performs this task and provides the results to the entire aerospace community.

\section{B. Making the case for commercial operations using the Government's fixed infrastructure while performing technology maturation operations on its commercial un-manned flights for the Government}

The technology readiness level (TRL) 6 level of technology maturation required the technology be flight tested which requires the same ground infrastructure for support as the commercial flight operations. Therefore, if the commercial operation can accept the risk of flying non-flight tested technology, they can use the same infrastructure and even the same flight systems. This approach will create an environment that allows the commercial operation to close its business case easily. At the same time the commercial operator will be conducting operations at a higher productive level with this new technology increasing his profit margin. If the government accepts the responsibility to develop and employ the infrastructure required to habitat space, this newly matured technology will reduce its cost as well.

In summary, opportunities for the commercial space operator to partner with the government sharing a common infrastructure are many. Similar to space act agreements, the benefits can be obtained for both the government and the commercial operator when forming this partnership. However, the option explored here of applying the new technology to the same flight vehicle being used to place cargo in earth orbit is new, but will add to the benefits of both parties. The greatest benefit of all from this partnering will be the resultant reduction in space transportation cost to earth orbit with greater availability. Another major benefit is the acceleration in commercial space operations activities.

\section{Advanced Technology Maturation Process}

\section{Making the case for the need of technology maturation}

\section{A. Why did Shuttle cost so much and what were the major cost drivers:}

First we must understand what the assumptions were that drove the design of the shuttle space transportation system. The objective of the shuttle system following the lessons learned from the Saturn/Apollo was to achieve a major cost reduction in transportation operations cost. The concept of operation was to provide a system that could be turned around on the ground in 160 hour and have an average space stay time of 7 days. Also the system would be capable of delivering 65,000 pounds to low earth orbit. Assuming theses transportation characteristics, a fleet of four orbiters could each fly ten flights a year or a total of forty flights per year. This capability would meet the needs of all the U.S. governments and the commercial's space transportation requirements for the next ten years. With these characteristics the shuttle would have achieved a much lower operating cost - projected to be maybe as low as $\$ 300.00$ /pound to low earth orbit.

Unfortunately, the design did not focus on these requirements, but instead placed all their focus on meeting the 65,000 pounds to orbit without regard to ground turnaround time or cost per flight. The only exception was the expendable element, e.g., the external tank of the shuttle system, which component reliability was designed with a focus on keeping the production cost and schedule low with the understanding that extra processes could be added later if needed to reduce weight at an added cost to the production. The ET requirement's greatest challenge was to build 400 units in ten years from a single facility. These compromises provided an orbiter system that could only fly approximately 2.5 times a year instead of ten times a year. This also lengthens the single vehicle ground flow time by a factor of four and caused an increase in hardware failure requiring replacement each turnaround operation. The 160 hour ground flow time became approximately four times this value ( $25 \%$ productivity). Weights saving measures also cause the flight systems integrity to be broken during each ground operation and this creates a need to re-establish the system's integrity before committing the system for flight. Lesson learned is that using the objectives to design to operation's needs must be primary and addressing lift (mass) to orbit will follow which is similar to the process used for the military. This can produce a system with much lower operating cost and be more productive. Weight reduction can follow after the system has accomplished its developmental test flight phase. Major upgrades to correct these deficiencies in the orbiter and solid rocket booster (SRB) elements could have brought about a large cost reduction in operations of the shuttle program. However, some of the changes require the use of advanced technology components that haven't been flight demonstrated. These lessons could also be used to develop a second generation reusable space transportation system that could provide a much more affordable system that could be sustained while moving forward with mankind's development and habitation of space. Because of 
flight safety concerns, demonstrating advanced technology through actual flight should be accomplished with unmanned flights.

\section{B. Why do we need advance technology?}

Achievement of the single orbiter productivity to meet the original requirements can be best achieved by using advanced technology which is mainly only lacking flight demonstration in many cases. This flight demonstration is for establishing the maturity required to be acceptable for inclusion in the design. For insight into their importance, we will list some of these advanced technologies later. Many of these advanced technologies will not only reduce the ground turnaround time by eliminating functions to be performed, but will increase the overall systems reliability and improve the flight system maintainability. They will also allow retaining the flight systems integrity between flights while eliminating many ground operations.

\section{Advanced technology demonstration capability is needed for the maturation process:}

The present NASA technology program's technology maturation scale is 1 through 9 . Their technology funding only covers TRL 1 through 6 with the actual flight demonstration being accomplished at the TRL 7 level. The need for flight demonstration, an extension to the government's research and development (R\&D) program (TRL 7-8), is required for accepting this technology in the future systems to reduce the large cost and schedule risk to a new system development.

\section{Why is space flight demonstration needed?}

NASA's programs are reluctant to use technologies that have not accomplished the TRL 7 successfully unless it is mandatory to use this technology. However, if other technologies are available even though they are counterproductive to achieving one of the primary objectives, they will be used to allow a lower development cost and schedule. Performing the TRL 7 flight demonstration could be a large impact to the front of the development schedule.

\section{E. A Few Advanced Technology Needs Examples}

There are many advanced technologies that have been developed through the TRL 1-6 levels, but require flight demonstration which is considered to be much more costly than the lower TRL level developments.

1.) Replace traditional distributed hydraulic control systems with either electro-mechanical devices or selfcontained electro-hydraulic devices that use distributed electrical systems.

2.) Replace traditional distributed pneumatic control systems with electro-mechanical devices.

3.) Better integration of electrical and propulsions by using a turbo-alternator driven from the main propellant pressurization systems to supply large electrical demand required during accent to orbit. Allows minimum sized batteries when main propulsion system isn't operating.

4.) Discontinue all toxic fluids by either better integration of like functional systems or selecting a much more operational friendly fluid. Nitrous oxide $\left(\mathrm{N}_{2} \mathrm{O}_{2}\right)$ should be given consideration for use where the need is for a storable oxidizer fluid. Propane should be given consideration for use as the fuel if the need is for a storable fuel fluid. These choices would be very friendly to ground operations and very safe and simple for flight operations; however, there are other choices that might be considered provided the ground or flight servicing is kept simple and friendly. These choices are not for maximum performance, but instead driven by lowering the life cycle cost (LCC) by only needing a simple servicing approach with its low cost facility. Systems that would be considered for these fluids are the reaction control system (RCS) and orbital control system (OMS).

5.) Simpler vehicle fluid tankage architectures that are serviced at ground level and do not require towers or long masts.

6.) Simpler rocket engine/propulsion architectures that are quick to fill and do not require active thermal conditioning to meet engine start conditions.

7.) Flight vehicle fluid tankage architectures (concentric tanks) for space operations that automatically provide thermal protection to avoid large losses for long duration operations. 


\section{Observations and Conclusions}

\section{Design Reference Markets Focus Space Transportation Architectures on all the Needed Attributes}

The specification of markets with quantified payload mass and seat delivery rates, with cost sensitivity to demand also quantified is of great utility to the space transportation architect. A design reference market provides a technical basis to build space transportation systems around the life cycle performance of the architecture, and not just optimize the mission performance as is often done with a design reference mission.

\section{Why combine these commercial space operations with Government space Technology maturation?}

Government provides the infrastructure as in other transportation needs of this country - highways. The NACA/NASA developed many technologies for the aircraft industry that were common to all who wanted to build aircraft. NASA is still developing advanced technology for this industry. The infrastructure needed to do this technology development is very expensive to build and maintain; therefore, no single industry unit should bare this expense as the return on investment isn't attractive for entrepreneurial investment. Therefore, progress can only be achieved if the government performs this task and provides the results to the entire aerospace community.

Making the case for commercial operations using the Government's fixed infrastructure while performing technology maturation operations on its commercial un-manned flights for the Government

The TRL 6 level of technology maturation required the technology be flight tested which requires the same ground infrastructure for support as the commercial flight operations. Therefore, if the commercial operation can accept the risk of flying non-flight tested technology, they can use the same infrastructure and even the same flight systems. This approach will create an environment that allows the commercial operation to close its business case easily. At the same time the commercial operator will be conducting operations at a higher productive level with this new technology increasing his profit margin. If the government accepts the responsibility to develop and employ the infrastructure required to habitat space, this newly matured technology will reduce its cost as well. This approach will greatly reduce the government's cost for technology maturation in that the need for a government developed, operated, and maintained flight demonstration vehicle will be eliminated.

Opportunities for the commercial space operator to partner with the government sharing a common infrastructure are many. The benefits can be obtained for both the government and the commercial operator when forming this partnership - like a space act agreement. However, the option explored here of applying the new technology to the same flight vehicle being used to place cargo in earth orbit is new, but will add to the benefits of both parties. The greatest benefit of all from this partnering will be the resultant reduction in space transportation cost to earth orbit. Another major benefit is the acceleration in commercial space operations activities.

The purpose is to encourage the commercial space transportation entrepreneur to team with another partner working with another objective but use a common ground infrastructure. This will allow the commercial space launch provider to be more competitive for the worlds markets and bootstrap the U.S. back into the commercial launch business as a delivery leader. In 2012 the SPST provided an example suggesting the space launch be provided by air launch capability as its first stage, but also to use this first stage airplane to transport cargo to all parts of the world at high speeds that aren't being offered today. Teaming with the government to use the space transportation system to deliver payload to space commercially can lower the operational cost of the operation by allowing the flight system upgrades with new unproven advanced hardware (flight test demonstration). This approach will also provide flight demonstrated hardware that can be used in the designs of future space transportation systems allowing the achievement of lower life cycle cost operations and thus making the U.S. more competitive in the world market and reducing the U.S. government's life cycle cost of space operations beyond low earth orbit.

Market availability also has an influence on this annual launch rate which will determine the commercial provider achieving his maximum potential — and new markets are need (see Attachment 1). 


\section{In Summary}

This paper established an example design reference market that established the needs goals, and objectives for space transportation architectural design. Such a reference is needed for establishing systems analysis parameters and early concept development-such as the two notional vehicle architectures pursued by the SPST in 2012 in its technical paper "Approach to an Affordable and Sustainable Space Transportation System" (References 6 and 16).

Most importantly, opportunities for expanding the commercial market in space are numerous. The commercial space venture investigated that engages youngsters stimulating their interest in the science, technology, engineering, and math (STEM) fields of education through access points at publicly- or privately-run science centers, planetariums, museums, entertainment parks, or existing visitor facilities located at NASA space centers is fascinating. Partnering and partitioning infrastructure for both public-private uses would greatly reduce the LCC for both the government and the private entrepreneur. Similar to space act agreements, implementing such a process today should not be difficult. The scale of this type operation would be unprecedented. Implementing this partnering process in accomplishing advanced technology maturation would greatly reduce the LCC of earth to orbit operations and enable space development and habitation significantly. At the same time this effort would generate much interest in the STEM fields for our youth giving the U.S. continued leadership capability in space exploration.

Follow on work by the SPST will include exploring more structured definitions for design reference market specification, as well as a more quantified examination of the economic and technology implications of pursuing public-private sharing of space transportation operations and infrastructure assets and liabilities. 


\section{Attachment 1-Space Market and Space Transportation Trends}

Example trends that demonstrate the need for U.S. exploration of new space markets can be seen in these two trend charts. The top chart shows that the number of space payloads is stalled, and that the U.S. can benefit from opening new space markets. The bottom chart shows that the space transportation market, as measured by the number of flights is stagnant, and that commercial space could benefit from opening new space markets.
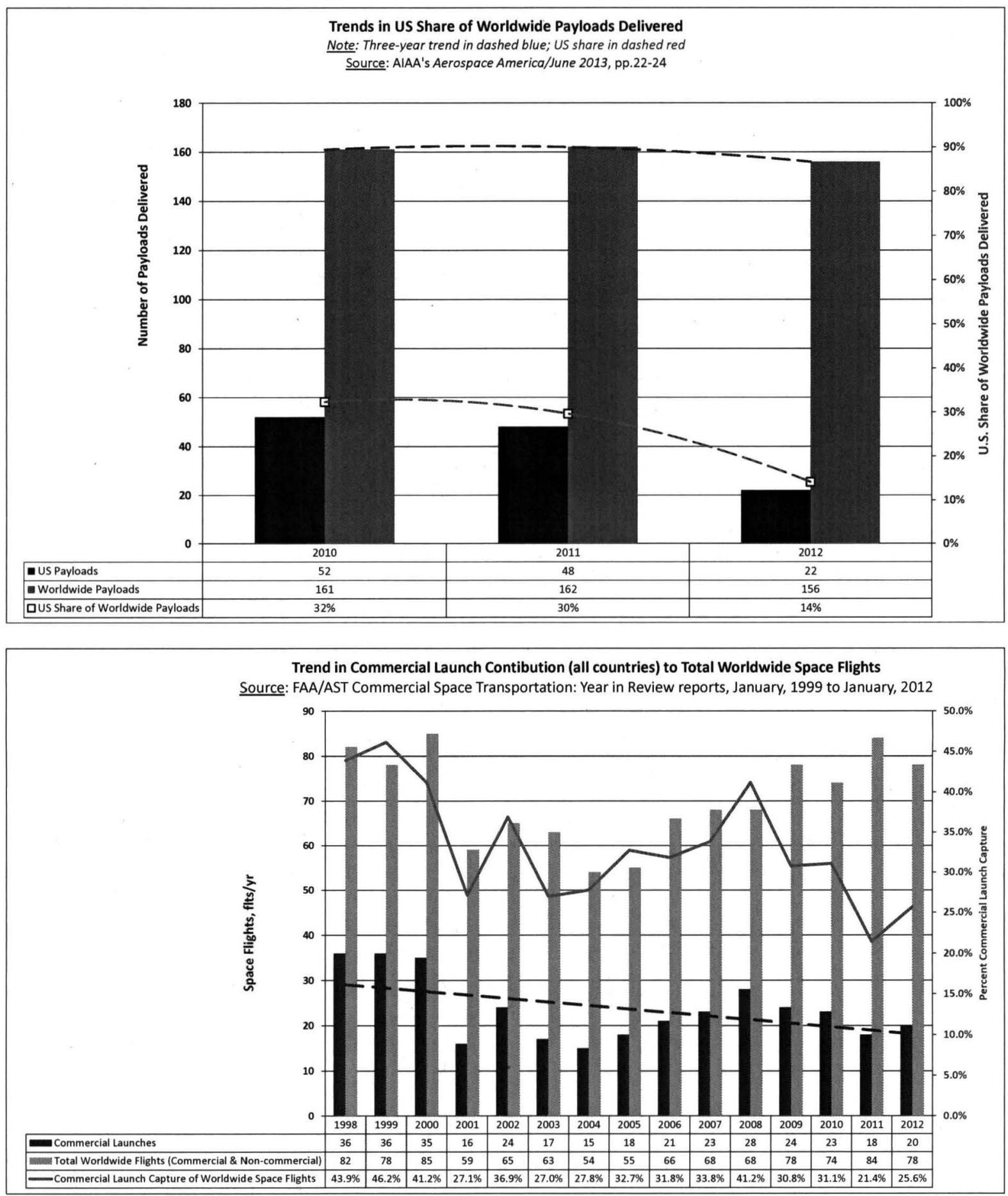

American Institute of Aeronautics and Astronautics 


\section{References}

\footnotetext{
${ }^{1}$ NASA Headquarters' "Commercial Space Transportation Study" web site url: http://www.hq.nasa.gov/webaccess/CommSpaceTrans/

${ }^{2}$ David, Leonard, and Kallender, Paul, Space News, June 10-16, 1996, p. 20. Taken from interviews with James Dunstan, executive vice president of LunaCorp; David Gump, president of LunaCorp, Arlington, Virginia; and William "Red" Whittaker, chief scientist of the Robotics Institute at CMU.

${ }^{3}$ McCleskey, Carey M., Using the Shuttle Columbia to Begin Bringing the Moon to America; technical paper published in the Proceedings of the Thirty-Third Space Congress; Cocoa Beach, Florida, April 25, 1996.

${ }^{4}$ NASA Headquarters' "Commercial Space Transportation Study," Figure 3.6.1.1-1. Nominal Annual Transportation System Demand Grows With Reduced Price to LEO; web site url: http://www.hq.nasa.gov/webaccess/CommSpaceTrans/SpaceCommTransSec36/CommSpacTransSec36.html

${ }^{5}$ NASA Headquarters' Cost Analysis Division, "2011 NASA New Start Inflation Index use in FY12," web site url: http://www.nasa.gov/pdf/601957main_2011\%20NASA\%20New\%20Start\%20Inflation\%20Index\%20use\%20in\%20FY12.pdf

${ }^{6}$ McCleskey, C. M., Henderson, E. M., Lepsch, R. A., Rhodes, R. E., Robinson, J. W.; AIAA technical paper, AIAA-2012-4153, "Approach to an Affordable and Sustainable Space Transportation System," 48th AIAA/ASME/SAE/ASEE Joint Propulsion Conference, AIAA, July 31, 2012. [Herein cited as: AIAA-2012-4153]

${ }^{7}$ Space-X website: http://www.spacex.com/falcon9.php, cited May 23, 2013.

${ }^{8}$ AIAA-2012-4153, p. 8.

${ }^{9}$ AIAA-2012-4153, p. 8.

${ }^{10}$ AIAA-2012-4153, p. 8.

11 AIAA-2012-4153, p. 8.

${ }^{12}$ AIAA-2012-4153, p. 8

${ }^{13}$ Joyner, C. R., II , Levack, D. J. H., and Rhodes, R. E., Robinson, J. W., "Propulsion System Choices and Their Implications," AIAA technical paper, AIAA-2010-6504, presented at 46th AIAA/ASME/SAE/ASEE Joint Propulsion Conference, Nashville, Tennessee, July 25-28, 2010.

${ }^{14}$ McCleskey, C. M., Rhodes, R. E., Chen, T. T., and Robinson, J. W., "High-Payoff Space Transportation Design Approach with a Technology Integration Strategy," Technical paper AIAA 2011-5571, presented at 47th AIAA/ASME/SAE/ASEE Joint Propulsion Conference \& Exhibit, San Diego, California, 31 July - 03 August 2011.

${ }^{15}$ AIAA-2012-4153

${ }^{16}$ Garcia, J, et al, ; AIAA technical paper, AIAA-2012-4152, "A Systems Approach to Developing an Affordable Space Ground Transportation Architecture using a Commonality Approach," $48^{\text {th }}$ Joint Propulsion Conference; Atlanta, Georgia, August 1, 2012.
} 